\title{
Animals, Cognitive Disability and Getting the World in Focus in Ethics and Social Thought: A Reply to Eva Feder Kittay and Peter Singer
}

\author{
Alice Crary
}

(C) The Author(s) 2018

Let me start by expressing my gratitude to Eva Feder Kittay and Peter Singer for agreeing to participate in this forum, and to this journal's editors for proposing and organizing our exchange. For the sake of convenience, I refer to the essay of mine to which Kittay and Singer have responded, "The Horrific History of Comparisons between Cognitive Disability and Animality (and How to Move Past it)," simply as $H H$ (For a summary of the essay, see above; for the full text, see Crary 2018a). My larger goal in writing $H H$ was to describe, and to lay the groundwork for an appropriate response to, horrific ways in which - in many parts of Europe and the Anglophone world-comparisons to animals have been used in rhetoric urging the subordination, abuse and killing of human beings with cognitive disabilities. More specifically, I wanted to show that we can and should affirm the equal value of the lives of cognitively disabled human beings without rewriting into our discursive practices the subjugation of animals that is internal to such rhetoric. With an eye to this goal, I set out to identify philosophical resources for defending an unqualified notion of human moral equality, and for combining this notion with an image of animal lives as having a sort of moral importance that doesn't somehow situate them below humans.

This project poses a direct challenge to members of the influential group of contemporary animal advocates who take reflection on the lives of intellectually impaired human beings to undermine the classic idea of human moral equality, and who insist on this point because they think that any plausible attempt to establish the moral standing of animals commits us to downgrading the standing of these human individuals. Taking my cue from the fact that Singer is the most prominent animal advocate whose work fits this description, I decided to frame $H H$ as a commentary

\footnotetext{
A. Crary $(\bowtie)$

Oxford, UK

E-Mail: alice.crary@regents.ox.ac.uk
} 
on a public debate that, in 2008, Singer had about relevant issues with Kittay, a similarly high-profile advocate for the cognitively disabled. The point of departure for my commentary on this dispute is an observation about its philosophical structure. Singer and Kittay were operating with fundamentally different assumptions about what is involved in bringing the world into focus in ethics, and, as a result, they to a significant extent talked past each other. In writing about their decade-old exchange, I expressed sympathy for the basic assumptions about these matters that are implicit in Kittay's remarks, and I attempted to show that her assumptions equip us to argue for a conception of human moral equality that is compatible with the view that animals have a non-inferior type of moral standing. But, before developing an argument to this effect, I described the philosophical logic of Singer's position, bringing out how his moral conclusions can seem defensible when considered in the light of his metaphysical and epistemological presuppositions. My goal was, by this route, to make it clear that, at a fundamental level, the quarrel between Singer and Kittay was a philosophical one, and that there was no way to arbitrate it without at least tacitly grappling with its philosophical stakes. I hoped to prompt a conversation between Singer-inclined animal advocates and Kittay-inclined advocates for the cognitively disabled that-instead of fruitlessly rehashing opposing moral claims that appeal only to those who are already inclined to advance them-took a more productive turn, beginning from a critical examination of the credentials of the diverging philosophical commitments that make the respective claims seem reasonable.

As far as the current forum is concerned, I only partially achieved this aim. In her gracious and insightful response to my article, Kittay notes that I am concerned with different philosophical conceptions of how we go about - to again use a phrase from my article that she cites (and that I myself learned from John McDowell)_- "getting the world in view" in ethics, and she discusses the significance of the particular philosophical conception she favors. But Singer's response, while attractively compact and forceful, is at bottom merely a restatement of his familiar view of human and animal moral standing, as well as of his familiar ideas about the relevance of animal-cognitive disability analogies to establishing this view. It's not merely that Singer does not here broach the topic of the merits of the philosophical considerations that seem to give his larger moral vision its appeal. There is no hint in his response of the recognition that it might be morally and philosophically relevant to do so. Bearing these observations in mind, below I summarize a central strand of $H H$ 's critique of Singer, showing that his response to it here is a non sequitur and that, faced with a fundamental challenge to his moral and philosophical beliefs, he has simply ducked. Then I comment on some of Kittay's reflections that bear on the issue that mainly concerns me, that is, how to think about human and animal moral standing in a manner that enables us to unwaveringly defend the equal importance of the lives of human beings with cognitive disabilities while at the same time maintaining that the lives of animals matter in a non-inferior manner.

Response to Singer We need to have before us some very general features of Singer's ethical posture. One of his guiding thoughts-implicit in his remarks, above-is that any moral solicitude that beings warrant is based on their individual 
capacities, in particular, on their capacities for pain and pleasure. Starting from this thought, Singer argues that consistency compels us to allow that any capacities that are morally germane in humans are equally so in animals. That is the gesture of his that underwrites both his attractive claims about the moral standing of animals and his jarring claims about the moral standing of cognitively disabled humans. With an eye to showing that animals are proper objects of moral concern, he raises a question about whether some humans and some animals are similarly endowed with what he regards as 'morally relevant capacities', and he defends an affirmative answer by adducing what he regards as evidence for thinking that humans who, say, as a result of congenital conditions, are seriously intellectually impaired are no better equipped than many animals with such capacities. Singer's thought about how moral standing is grounded in individual capacities is thus decisive in leading him to traffic in comparisons between cognitive disability and animality. This is apposite because he relies on such comparisons in attempting to show, not only that some animals merit greater solicitude than they receive, but also that cognitively disabled human beings have diminished moral standing and that reflection on their lives speaks against affirming an unqualified notion of human moral equality. Animal comparisons are a key device in his case for thinking that it would be a sign of - to use one of his terms of art-speciesism (or unwarranted favoritism for a particular species) to represent merely being human, regardless of the level or character of one's cognitive capacities, as morally important.

When I intervene critically in Singer's work in $H H$, I ask why should we accept the thought from which he here begins his reflections. Why, that is, should we follow him in taking moral standing to be grounded in individual capacities? Or, more generally, why should we follow him in taking the moral standing of human beings and animals to require grounds? That Singer believes grounds are needed can, as I point out in the essay, be traced to an assumption he makes to the effect that the plain fact of being human, or of being an animal of some kind, is morally indifferent. He takes facts of these sorts to be observable or theoretical circumstances, and his tendency to regard such facts as in themselves morally indifferent is a function of his larger philosophical commitments.

Singer has, throughout his career, worked primarily in professional circles in which many philosophers hold that there are no moral values in the real fabric of the world, and he himself used to espouse a form of ethical non-cognitivism that presupposes a metaphysical outlook fitting this description. Today, in contrast, he favors a form of rational intuitionism on which some objective ethical truths supposedly reveal themselves to intuition. But since, as he sees it, the class of truths that thus show themselves includes only a few very general practical precepts, he effectively continues to hold that empirical circumstances—such as, e.g., the plain fact of being human or the plain fact of being an animal of some kind-are, qua observable, devoid of moral significance.

This metaphysical posture has a notable epistemological counterpart. Philosophers who maintain, as Singer did early in his career, that the furniture of the universe is devoid of moral values are frequently led to this view by the thought that our subjective endowments tend essentially toward distorting our view of how things really are. The idea is that we approach an unimpeded image of the world by 
progressively abstracting from every mode of subjective responsiveness and by, at the same time, progressively eliminating from this view any qualities that contain essential references to attitudes and other subjective responses. This idea in turn seems to exclude the possibility of moral values in the real weave of the world. To the extent that moral values are understood, in a familiar and appealing manner, as internally linked to attitudes, the idea that steps toward a more accurate vision of reality are necessarily steps toward abstraction will seem to bequeath to us a conception of reality on which it is devoid of these values. Now it appears that the route toward a less distorted view of the world essentially involves abstracting from our attitudes and thus approaching ethical neutrality. Within $H H$, I spoke in this connection of a neutral conception of reason, and I noted that, although Singer's metaphysical convictions have changed in the relatively modest ways just touched on, he has consistently operated with this conception.

This is the core aspect of Singer's signature stance that, within $H H$, I identify as a legitimate object of moral and philosophical criticism. I refer to attacks on the neutral conception, including some that I myself have launched, that get levelled within philosophical debates about how to construe the notion of objectivity (see Crary 2016, 2.1 and Crary 2018b), and I argue that, absent the neutral conception, it is unclear why we should think Singer is justified in maintaining that the mere fact of being human, or of being an animal of some kind, is morally unimportant. The upshot is that it is unclear, not only why we should follow him in trying to locate for grounds for human and animal moral standing, but also, by the same token, why we should follow him in basing moral standing in individual capacities of mind in a manner that seems to oblige us, when we are thinking about questions of ethics and animals, to make use of historically fraught and politically problematic analogies between animals and cognitively disabled human beings.

Perhaps these observations would seem uninteresting in the absence of a plausible competing approach to moral standing. Yet $\mathrm{HH}$ also shows that Kittay is-at least in some portions of her work-adopting a more satisfactory, alternative approach to human moral standing, specifically, one that depends for its appeal on rejecting the neutral conception of reason. The essay addresses above all parts of Kittay's work in which she claims that to properly bring a human being into focus in ethics we need to look at her from a non-neutral, engaged or caring, stance. Additionally, she sometimes suggests that bringing human beings adequately into focus in ethics is inseparable from seeing them as morally important, and she asks us to regard these considerations as holding for all human beings, not merely the cognitively typically endowed. Kittay has devoted much of her professional life to making these points in reference to her daughter Sesha who-as Kittay puts it in her response to $H H$ for this journal- "in addition to physical disabilities such as epilepsy, and communication disabilities...can't speak...has very significant cognitive disabilities which disallow her from doing much with her hands, make walking and balancing very difficult and which interfere with intellection." A very attractive feature of the alternative approach to human moral standing that Kittay develops in this personal style is that it equips us to champion the idea of human moral equality. 
In $H H$, I describe Kittay's approach and lay out resources for a persuasive defense of it. In addition to referring to the criticisms of the neutral conception touched on a moment ago, I refer to work in philosophy of mind from which it follows that aspects of mind should be regarded of features of the world that we can only recognize if we look at them from non-neutral perspectives. In this connection, I turn to work of Ian Hacking's on autism that supports Kittay's claims about Sesha's moral standing, and I also describe how Hacking's argument can be elaborated in support of an analogous account of animal moral standing. In light of these features of $H H$, one thing that is arresting about Singer's response to the essay is that he doesn't present himself as confronted with an alternative account of moral standing. It's not merely that he doesn't try to justify his neglect of the Kittay-style account that I defend; he doesn't acknowledge that an alternative account is in the offing. To the extent that he can be construed as offering an excuse for this attitude, it is insofar as he reminds us of his laudable and well-known commitment to, as he puts it here, addressing "the pain and suffering we humans inflict on a trillion or more sentient vertebrate animals each year." He seems to be suggesting that the immensity of the horror of what is done to animals justifies him in sticking to moral views that, in his words, "may operate to the disadvantage of cognitively disabled humans." Whatever its merits, this suggestion has no bearing whatsoever on the conversation in which Singer is at present involved. An important project of $H H$ is, as I just mentioned, laying out a case for the moral standing of animals that is analogous to the essay's case for the moral standing of humans and that, moreover, is an improvement over Singer's own case in that it is explicitly opposed to the idea that animals are morally inferior to human beings (More about this in a moment.). In a forum about $\mathrm{HH}$, Singer's expressions of his concern for animals, however appealing and praiseworthy in themselves, are cleanly beside the point. More generally, his insistence on simply repeating the view of moral standing to which his concern leads him is here likewise a bit of argumentative irrelevance. Singer has been confronted with a philosophically serious and morally urgent criticism of his view of animal as well as human moral standing, and he has chosen, inexplicably, to keep on along as though nothing has happened.

Response to Kittay In her generous remarks on $\mathrm{HH}$, Kittay underlines the interest of some of the essay's explicit claims and spells out some consequences of its argument that I left merely implicit. She in these ways gives me a welcome opportunity to underline and further spell out the interest of the larger project. Let me start with the moment in her response at which Kittay credits me with exposing a significant "irony" in, as she puts it, Singer's use of the term "speciesism" to "evoke for us other pernicious 'isms' such as racism." Singer's contention that speciesism, as he understands it, is akin to racism and sexism is ironic because he arrives at his particular conception of speciesism by appealing to comparisons between animals and cognitively disabled human beings and because, in Kittay's words, "comparisons of denigrated groups to animals do not stop with the cognitively disabled," having been significant mechanisms in the production of various violently oppressive forms of racism and sexism. Indeed, as Kittay notes, the irony is deeper insofar as some significant strategies of oppressive 'animalization' have been used to simul- 
taneously subject cognitively disabled human beings and members of marginalized racial groups. Kittay is right that this is an important theme of $H H$ (see also Crary 2019). I focus within the article on the role of animal comparisons in the arguments and propaganda that the Nazis used to justify the murder of 200,000 psychiatric patients. To illuminate the logic of these comparisons, I turn to influential strands of thought from Darwin's Descent of Man, where Darwin defends the idea of a linear animal-human scale on which some human races are "lower" in a sense that involves being closer to non-human animals and on which "idiots" are recursions to earlier, pre-human stages and hence "lowest" and most closely linked to non-human animals. Despite his opposition to slavery, Darwin presents this ordering of human beings and animals as having normative significance, thereby-through the use of animal comparisons-effectively laying the groundwork for the terrible eugenic violence of the next century that was in fact simultaneously racist and ableist. Hence what Kittay calls the "irony" of Singer's use of animal comparisons to combat forms of "speciesism" he takes to be analogous to racism.

Singer's typical response to observations along these lines is that it is alright for him to make use of these comparisons, despite their pivotal role in pernicious racist and ableist discourses, because his own thinking is untainted by noxious political views. Moreover, he himself thinks animal lives matter, so there is, as he sees it, nothing essentially degrading about animal comparisons. $H H$ likewise defends the view that animals have moral standing and hence that animal comparisons are not essentially harmful. But this is not a good endpoint for thought about these matters. Given the history of the use of animal comparisons to subjugate members of vulnerable social groups, we have compelling political reasons to exercise extreme care, of a sort not exhibited by Singer, in-as I put it in $\mathrm{HH}$ - "tracing out lines of filiation between the lives of animals and the lives of members of human groups who confront systematic forms of bias." Kittay is expressing a congenial idea when she reminds us that "words carry the historical accretions of their usage," and she goes on to say pointedly to Singer that "when asking how a person or class of persons who have a history of being denigrated differ morally from a pig, it makes little difference that the speaker evinces a great fondness for pigs." The one thing I would add to this - and I hope and imagine that Kittay will sympathize with the addition-is that we need to be flexible enough in our thinking and in our politics to make room for insightful and politically sensitive attempts to reclaim animalizing devices that have historically been used hatefully, such as, for instance, the work of the disability scholar Sunaura Taylor (see Taylor 2017), who was from early childhood denigrated by being compared to animals, and who has worked to revalue and affirm the comparisons with an eye to combatting what she rightly sees as interlinked forms of ableism and disdain for animals.

This brings me to the moment in Kittay's response in which she concurs with my suggestion that, in attacking callousness and cruelty to animals, our efforts should be directed not at the idea that all human beings matter equally but rather "at the normatively infused hierarchy that is used to justify human dominance over all that is nonhuman." A key philosophical aim of $\mathrm{HH}$ is to sketch twin arguments for human and animal moral standing that equip us to lay claim to human moral equality while also representing animals as mattering in a non-inferior way-arguments that 
are thus a direct rebuke to the very idea of a normative hierarchy of life-forms (Although I don't discuss this in $H H$, hostility to this idea is a leitmotif of the work of leading ecofeminists such as Carol Adams and Lori Gruen.). My main resource for challenging the idea of a normative ranking of life-forms is the set of reflections on philosophy of mind, mentioned above, which I argue can be used to show that all human beings and all animals matter just as the kinds of creatures they are. It matters to me-I am myself a moral vegan and a committed animal advocate- that the outcome is an argument for animal moral standing that gives us no reason to be defensive about Singer's presentation of himself here as the only animal advocate in the room because it in fact goes farther than his argument. As I put it in $H H$, Singer preserves "a human-headed ranking of life-forms insofar as he ties creatures' moral status to [] individual capacities" of which human beings typically receive the biggest 'morally relevant' portion. He thus weakens his own advocacy on behalf of our fellow creatures.

Consider in closing the issue that Kittay makes the centerpiece of her response, viz., her agreement with my contention that Singer was wrong to demand that she specify individual capacities to ground her claims about her daughter Sesha's equal human moral importance. Insistence on such grounds for human moral standing is what leads Singer to deal in animal comparisons, and this traffic in the comparisons is problematic and objectionable, not only because it encourages the further marginalization of an already vulnerable group of human beings, but also because, with regard to the quest for a better understanding of the value in human life, it encourages us to look resolutely_-in Kittay's phrase_- "in the wrong place." Nor is Singer's insistence on grounding moral standing in individual capacities any more appropriate in the case of animals. A core conclusion of $\mathrm{HH}$ is that, if we are to progress in our efforts to appreciate the moral standing of human beings and animals, we cannot get distracted by Singer-style (or other) ethical theorizing that turns our attention away from the worldly lives of human beings and animals. Instead we need to struggle for finer and more sensitive attention to these lives, where struggling essentially involves working on ourselves to cultivate or refine our sense of what matters.

This means that there can be no question of getting aspects of the world, such as human and animal lives, in view in ethics simply-in the manner envisioned by Singer-by attending to them in a manner purged of pernicious prejudices. What is required in addition is an active effort to develop ourselves. At issue is an effort-this is a point that follows from $H H$ 's main argument_of a sort that may be essentially assisted by social movements, works of art and counterpublics that invite us to place importance on things that might once have struck us as unimportant. This lesson about what doing justice to the value in human and animal lives demands is of immense significance right now, at a time at which practices and institutions that involve the slaughter of many billions of animals annually continue largely unabated, at which pernicious racist and ableist ideologies that are descendents or close cousins of those discussed in $H H$ are again on the rise-and at which many of these lives are at risk of grave harm. 
Open Access This article is distributed under the terms of the Creative Commons Attribution 4.0 International License (http://creativecommons.org/licenses/by/4.0/), which permits unrestricted use, distribution, and reproduction in any medium, provided you give appropriate credit to the original author(s) and the source, provide a link to the Creative Commons license, and indicate if changes were made.

\section{References}

Crary, Alice. 2016. Inside Ethics: On the Demands of Moral Thought. Cambridge, MA: Harvard University Press.

Crary, Alice. 2018a. The Horrific History of Comparisons Between Animals and Cognitively Disabled Human Beings (and How to Move Past it). In Animalides, edited by Lori Gruen and Fiona Probyn Rapsey, London: Bloomsbury.

Crary, Alice. 2018b (forthcoming). Objectivity. In Wittgenstein: Basic Concepts, edited by James Conant and Sebastian Greves, Cambridge: Cambridge University Press.

Crary, Alice. 2019 (forthcoming). "Comments on a Contested Comparison: Race and Animals". In Ethics in the Wake of Wittgenstein, edited by Oskari Kuusela and Benjamin De Mesel, London: Routledge.

Taylor, Sunaura. 2017. Beasts of Burden: Animal and Disability Liberation. New York, NY: The New Press. 